\title{
BMJ Open Do special constables in London feel that they are adequately prepared to meet their first aid responsibilities? A qualitative study
}

\author{
Joht Singh Chandan, Richard Meakin
}

To cite: Chandan JS, Meakin R. Do special constables in London feel that they are adequately prepared to meet their first aid responsibilities?

A qualitative study. BMJ Open 2016;6:e010082. doi:10.1136/bmjopen-2015010082

- Prepublication history and additional material is available. To view please visit the journal (http://dx.doi.org/ 10.1136/bmjopen-2015010082).

Received 28 September 2015 Revised 3 January 2016 Accepted 13 January 2016

CrossMark

Department of Primary Care and Population Health, UCL Medical School, London, UK

Correspondence to Joht Singh Chandan; Joht1@hotmail.com

\section{ABSTRACT}

Objective: This study's aims were to explore the views of special constables in the London metropolitan police force concerning their obligations and skills as first aiders.

Background: The metropolitan police force provides police officers to act as first responders to emergency calls made by the public. Special constables act with the same powers and responsibility as police officers and are required to deal with incidents involving medical emergencies.

Setting: West London Police Station.

Participants: Fifteen special constables entered and completed the study.

Methods and Outcome Measures: A qualitative study involving semistructured interviews, participant observation, and reflective work. The outcome measures were the themes derived from the 'thematic framework approach' to analysis.

Results: Four main themes were identified. (1) 'Our responsibility?'-Special constables felt they had a responsibility, but were unsure of the origin of this responsibility, with many feeling it stemmed from public expectation. (2) 'Confidence'-Special constables had mixed feelings regarding their confidence in first aid scenarios and many felt that more could be done to improve their confidence. (3) 'Training needs'-Many felt the current training system was lacking in several ways including regularity, teaching and content. (4) 'Personal first aid knowledge'-Special constables were disappointed with their past performances.

Conclusions: Owing to the small size of this study, the conclusions are limited; however, if the findings are confirmed by larger studies, they suggest the need to improve the confidence of special constables in first aid situations.

\section{INTRODUCTION}

Police officers act as first responders to a proportion of the 85000 emergency 999 calls made each day in the $\mathrm{UK},{ }^{1}$ and a proportion of these involve administering first aid. The

\section{Strengths and limitations of this study}

- A strength of the study was that it provided an in-depth exploration of views held by special constables regarding their role as first aiders. Little is known about the first aid readiness of this group of first responders.

- The data were triangulated using semistructured interviews, participant observation undertaken by the researcher, and a reflective diary.

- The principal researcher was a member of the group being studied, sharing many assumptions, beliefs and experiences of the group. However, the data were independently analysed by the second author (RM) and agreement was reached on the analysis, as the primary author's analysis could have been coloured by being part of the group studied.

- A limitation of the study was that the sample was recruited from one police station and was a convenience sample of 15 officers. However, theoretical saturation was achieved.

- This qualitative study provided an in-depth exploration of the views of one group of special constables regarding their role as first aiders. Further quantitative studies are needed to determine whether these views are generalisable.

Home Office ${ }^{2}$ considers 'preserving life and limb' among the key duties of police officers. Special constables (SCs) are police officers who hold full police powers but act in a voluntary capacity without pay. They train for 23 days before beginning a supervised probationary period until they are deemed competent to undertake duties independently. SCs often patrol in pairs but may also act alone. They report to the special sergeant at their police station, who is a fully qualified police sergeant who is also a volunteer. The role is designed to act as a way for individuals with an interest in a future policing career to develop their skills or for those with a strong interest in their community to provide a hands-on voluntary service. The year 2013 
marked the 20th anniversary of the death of Stephen Lawrence. The subsequent enquiry revealed that Lawrence's life could have been saved if the first responders had administered first aid competently. ${ }^{3}$ Since the report, there has been a restructuring of the metropolitan police's first aid training. SCs are provided with first aid equipment and a 2-day initial course covering basic 'emergency life support'. In addition, police officers must attend a half-day refresher course each year.

Little is known about how SCs in the UK view their responsibilities as first aiders. A US questionnaire study ${ }^{4}$ of 1130 police officers (82.2\% response rate) attempted to assess whether police officers felt confident when dealing with cardiac arrest situations. The results showed that only $35.6 \%$ of the police officers felt confident using a defibrillator. Another US study ${ }^{5}$ questioned police officers and discovered that 308 of the $420(73 \%)$ participants felt that knowledge of first aid is important to police officers. However, this research identified that police officers felt underprepared to perform their role. Also as less than a third of the law enforcement agencies supplied defibrillators to their police officers, they felt ill-equipped.

Other US studies considered whether police officers have a good understanding of emergency medicine. Sztajnkrycer $e t a l^{6}$ assessed police officers' understanding of first aid using vignettes seeking written feedback from them regarding their management. The results demonstrated the police officers' lack of knowledge when dealing with the nine case scenarios presented to them. Pfeffer $e t a l^{7}$ carried out a study in which police officers were trained together with emergency medical services personnel. Officers felt that they had gained greater knowledge following combined training plans rather than from police-specific training.

The majority of work in this area was carried out in the USA, and little is known about the situation in the UK. The majority of studies used quantitative designs, and it is unclear whether these were identifying the concerns of the officers involved or the areas identified by the researchers as being important. It is therefore important to identify the concerns of police officers working in the UK police service. In order to address this aim, we conducted an in-depth qualitative study.

\section{METHODS}

The study design was qualitative ethnography, as the principal researcher (JSC) is a member of the group being studied. JSC is a male medical student who also works as an SC. The study was undertaken as part of an intercalated BSc.

\section{Ethics}

Ethics approval was received from the Metropolitan Police Research Department and University College London Ethics Committee before the investigation. Both written and verbal informed consent was obtained from the participants. Interviews were conducted privately, and participants' transcripts were anonymised.

\section{Relationship between researcher, participants and metropolitan police}

The researcher and interviewees had a pre-established relationship from working together. The participants were aware that JSC was also studying medicine. The interviews were conducted with both researcher and participant in uniform. This may have made the participants more comfortable talking about their shared experience. As participants may have been concerned that JSC would judge their answers, they were assured that their answers were not expected to be 'right' or 'wrong'.

As JSC was a serving SC, it was necessary to consider his relationship to the metropolitan police force. He was given permission to independently design and carry out the study. However, his ethical and professional responsibility required him to report any serious negligent events that may have been discussed during interviews. Fortunately, this situation did not arise.

\section{Context and sampling}

The study was conducted at one police station in West London where JSC is based. The study took place over a 3-month period. JSC recruited a convenience sample of 15 SCs in the Special Constabulary Office before or after the SCs' shifts. Every officer on each shift was offered the chance to take part. All officers approached agreed to take part. Sampling ended when theoretical saturation was reached.

\section{Data collection}

Data were collected using predominantly semistructured interviews. However, JSC recorded any first aid events encountered by him in his capacity as an SC and his reflections on them as a participant observer in a diary. This diary also included comments on the semistructured interviews. Any iterative changes to the method of data collection or analysis were also recorded in the reflective diary. Participants were informed of the use of this reflective diary.

\section{Semistructured interviews}

Face-to-face semistructured interviews were carried out with 15 SCs by JSC at the police station. Demographic information was collected during the interviews. The interviews were conducted using a topic guide. Topics included SCs' responsibilities as first aiders, experience as first aiders, training and three vignettes (box 1) developed in collaboration with the metropolitan police first aid training team. The vignettes included knowledge that the officers should possess, but they were not used to test participants' knowledge; rather they were used to stimulate discussion and identify areas where the SCs may experience uncertainty. The interviews lasted up to $45 \mathrm{~min}$ each and were recorded. 


\section{Box 1 Vignettes}

Vignette 1: On patrol you come across an adult male in the park who is unresponsive, not showing signs of breathing and who smells of alcohol.

Vignette 2: You have arrived at the scene of a shooting as a first responder; the victim was shot in the chest, and the bullet appears to have penetrated the lung cavity creating an exit wound as well as an entry wound.

Vignette 3: You have arrived at the scene of a stabbing as a first responder; the victim has been cut across the face and appears to go into shock.

\section{Analysis}

The interviews were transcribed verbatim. Data analysis was undertaken in parallel with the interviews, enabling the topic guide to be modified in light of emerging themes derived from the data. The transcribed interviews combined with the data from the participant observation study and the reflective diary formed the raw data used in the analysis. The data were analysed using the "thematic framework approach' ${ }^{\text {, }}$ with the aid of NVivo 10 software. This process occurred in five steps.

1. Familiarisation with the raw data This took place through rereading the transcripts, the reflective diary, and any responses received through the memberchecking process, allowing JSC to list key concepts that appeared.

2. Identifying a thematic framework JSC selected recurring themes in order to create an index of data to label the transcripts and divide them into sections that corresponded to established key ideas and themes, providing the basis of the thematic framework.

3. Indexing the transcripts according to the ideas presented This stage was supported by the use of NVivo 10 software to index and highlight themes within the data.

\begin{tabular}{lll} 
Table 1 & Description of participants & \\
\hline Interviewee & Primary career & Time served \\
& as an SC \\
\hline 1 & Unemployed & 3 years \\
2 & Careers advisor & 15 months \\
3 & Sales assistant & 14 months \\
4 & Student & 11 months \\
5 & Agency work & 11 months \\
6 & Student & 11 months \\
7 & Driving instructor & 16 years \\
8 & Library manager & 6 years \\
9 & HR director & 3 years \\
10 & Martial arts instructor & 10 months \\
11 & Fire safety inspector & 1 year \\
12 & Customer advisor & 14 months \\
13 & Football coach & 1 month \\
14 & Community safety manager & 2 years \\
15 & Public servant & 3 years \\
\hline $\mathrm{HR}$, human resources; SC, special constable.
\end{tabular}

4. Charting the data NVivo 10 software was used to rearrange the highlighted sections of data into the area of the thematic framework to which they related.

5. Mapping and interpreting the data This involved the interpretation of the charts of data collected to obtain conclusions.

Initial analysis was conducted by JSC. The data were independently analysed by RM who supervised the study, and a final interpretation was agreed.

\section{Member checking}

All participants were sent a transcript of their interview and a summary of the researcher's analysis and asked for their comments. No amendments were requested by those who responded.

\section{RESULTS}

The participants are described in table 1 using less than three identifiable features to maintain confidentiality.

Four main themes were identified. Each of the themes possessed subthemes (table 2).

\section{Our responsibility}

Each of the 15 participants agreed in varying degrees that they had a responsibility to perform first aid if required. However, it is clear from the interviews that, although SCs accept that they have a responsibility to provide first aid, some value other aspects of their role more highly.

...my main focus is on, preventing crime, I see the first aid stuff as secondary, you know I didn't voluntarily join the LAS (London Ambulance Service) I joined the police (7)

Table 2 Themes identified

\begin{tabular}{ll}
\hline Theme & Subthemes \\
\hline Our responsibility & First aid obligations; \\
& professional, legal and moral \\
& Public expectations \\
Confidence & knowledence of first aid \\
& Being alone \\
& Emotional vs technical difficulty \\
& in first aid \\
& Equipment \\
Personal first aid & How confidence could be \\
knowledge & First aid knowledge \\
Training needs & Self-evaluation \\
& Continuity of training \\
& Other available training courses
\end{tabular}


First aid obligations; professional, legal and moral

Some believed that the responsibility arose from the basic tenets of the special constabulary, which involve the preservation of life, with some believing they had a legal responsibility.

the role is to safeguard public safety... you have, I feel, an obligation if somebody is having an injury or incident where they require first aid, then I am obliged to intervene, as part of being a police officer and give them first aid. (11)

The legal responsibility is part of our job profile. It's a contractual responsibility within the Met, you are required to perform first aid, so it's a contractual requirement in that they expect you to do it as oppose to statutory $(9)$

However, others did not believe they had a legal responsibility.

I believe it's not (6).

In addition, some believed responsibility stemmed from a moral obligation to utilise the knowledge taught.

...morally if you've been trained or even if you haven't been trained as a member of society I think my view is that you should provide help where you can and not to be a bystander or just walk away. I don't think walking away is acceptable since we have training, then we are obliged to use the training (11)

However, not all SCs felt they had a moral responsibility to help those in need and would only help if they were the only professional on hand.

I'd leave it to the professionals; a paramedic would be better suited than I would (2)

It is clear that, while they believe that they have a responsibility to provide first aid, there are varying views as to where this responsibility comes from.

\section{Public expectations}

There was also a belief among SCs that, although they have a duty to provide first aid, getting involved in these situations was driven to some extent by public expectations of their role as police officers, with some believing this was justified.

I think when people look at you they don't see the human side and see you're someone there to help and at whatever cost you have a duty of care to deliver first aid (13)

Obviously as a police officer you should care more for other people (5)

However, there was a belief that the expectations of the public were too high. ...we are like superman, when they see you in the uniform they see superman and expect you to answer everything (6)

Such high expectations can have an impact on SCs when carrying out first aid, resulting in SCs feeling under immense pressure to perform successfully. The researcher's reflective diary noted how participant 6's body language demonstrated how nervous it made him discussing public expectations.

However, some of the participants believed that it was important to live up to public expectations.

You always have to put on a brave face when you are out in the public to make them feel reassured and think you know what you are doing and also so they take you seriously and don't think you are a pushover (5)

\section{Importance of first aid knowledge}

Many SCs believed that, because they had the responsibility to provide first aid, knowledge of first aid was important to help them fulfil their duties.

Yeah absolutely because of the nature of the calls we go to, you know you often attend to victims of assaults, and robbery and so forth, and people generally in need of first aid, so by the very nature of what we do it is important we are able to administer first aid. (7)

Some SCs felt that first aid was so important that it deserved more attention than it currently receives.

I think it is because at the end of the day we are there to save lives and if it's something that can be done to save lives I'm sure many officers are confident in it...but I think it should be a higher knowledge than we have now (3)

\section{Confidence}

The confidence of SCs when dealing with first aid situations seemed to be determined by past personal experience.

...because of my background I probably am [more confident] (9)

Other SCs also felt quite confident in first aid situations by virtue of having had the opportunity to witness other police officers perform first aid.

I'm pretty confident as I have seen a few POs dealing with other cases, and I learn by looking at them (12)

However, not all the participants felt confident.

I don't feel confident enough [with regards to first aid skills] (10)

SCs explained that their confidence varied depending on the situation. Some felt confident in some situations but not others. 
I didn't see it but the guy's jaw was almost hanging off. In those situations I'm not sure what to do. If I came across any of the scenarios I've already come across in the past [real-life or training] I would feel confident (14)

\section{Being alone}

SCs expressed the view that the presence of a second police officer or SC was a source of physical, emotional and educational support, as they felt first aid to be a 'two-person job'.

Because it really is a two-person job, you need that person checking the pulse, to keep them awake if they're in shock whilst the other PO is doing something else (2)

Further, it appeared that the presence of another police officer or SC reduced the anxiety faced and provided reassurance to $\mathrm{SCs}$ in difficult situations.

I would have thought presumably similar [on my own] but it does help when you get in a panic sometimes. I think I could probably cope quite well, but then again I am always frightened in the back of my head (8)

A number of the participants believed that being with another police officer or SC was especially important for new SCs. However, all of the SCs agreed that the responsibility of an SC is the same whether they are new or experienced.

...as a new SC you rely heavily on the experienced SC and let them point you in the right direction, whereas on your own you have to get over that and use your own instincts a lot more (10)

\section{Emotional versus technical difficulty of first aid}

The confidence of the SC can be affected by the emotional as well as the technical aspects of the situation.

It was very horrible because I've never seen so much blood, they teach you about what will actually happen but not how you will actually feel. It was a bit of panic and a rush which I felt was very uncomfortable (10)

The researcher in his role as an SC attended a bleeding casualty, although the scenario was 'nerve-wracking' (Reflective diary), there remained a need to remain composed. Anxiety added to the pressure the researcher felt, which may have affected his judgements on the day.

\section{Equipment}

Some SCs believed the equipment they had at their disposal was an important factor in their confidence in dealing with first aid situations.

[After being asked the factors limiting confidence in first aid scenarios]...The equipment to be honest (4)

SCs believed that the current equipment available to them was not of a high enough standard to carry out the role.
The problem is we can carry everything or nothing, the more and more we carry, the worse it's going to be, but I think our first aid kits are very poor. You can always be over prepared but I think our first aid kits are very poor. (10)

\section{Improving confidence}

SCs expressed the view that there are several ways in which confidence can be improved. Some SCs believed that real-life experience improves confidence.

I'll tell you the truth, just dealing with the situation doing it in real life, practice makes perfect, experience is the key $(6)$

However, many SCs felt there was a strong link between the training they receive and their confidence. Several SCs believed that having more frequent training could greatly boost their confidence.

The best way to improve first aid like I was saying before is a bit more training or a refresher, because it's a scenario based situation so the more you practice the more likely you are to know what to do on the day. (11)

Others felt that not only improving the frequency of training, but also broadening the focus of the training may be helpful in improving their confidence.

The training is basically a repeat, so it would be quite nice to be given different scenarios which we would likely come across. I mean maybe some more training around knife culture and gun culture and serious youth violence would be quite useful as they are quite prominent (14)

\section{Personal first aid knowledge}

For some participants their personal first aid knowledge was derived from past experience and training received in the police.

\section{First aid knowledge}

Discussion of the vignettes during the interviews suggested that, although knowledge among the participants was good in some areas (vignette 1), it was less good in others (vignette 2). However, some SCs demonstrated some confusion about the practical procedure,

Err CPR err, through, I would put him in the position where I lift the chin, pinch the nose and then do mouth to mouth, err if I did not have a face cover, I would use my shirt as a barrier or find something to use as a barrier, or piece of...to stop...for my safety and also to stop err, to stop me from catching something, so I would look for a barrier, and then administer CPR (vignette 1, participant 11)

and the terms used.

It's usually an unexpected thing, I guess...Shock to me is when the body because of some trauma is unable to cope with the trauma emotionally and psychologically 
and even physiologically, the body goes into a state of alert and in that state the organs can be affected and if its serious you can die of shock, so it's a critical reaction of the body to trauma (vignette 3 , participant 5).

Some SCs also chose to focus on what they termed the more 'police' matters rather than the first aid situation, which may have reflected their lack of confidence.

...if no sign of life, first call the duty officer and it needs to be declared as a critical incident. Get Trojan officers down, check to see sign of life. If there is none, I would not touch the body, I would get a cordon around as far as I can and get a crime scene in place. If there is no sign of life and the person is cold and there is a hell of a lot of blood coming out of them, I wouldn't be doing anything to disturb the crime scene (vignette 2, participant 2)

\section{Self-evaluation}

Some SCs felt that they had performed well in their past experiences and that they could have done nothing more, while others were disappointed with their past performance.

...I could have done better. I had a frank and honest conversation with the regular officer after who said I needed to be a bit more prepared and she understood it was my first time so she was quite forgiving but she said I needed to be much more active. (1)

Several SCs were also disappointed with their responses to the vignettes presented in this study (especially vignette 2 ), but felt that they had tried their best.

...the gunshot one could have been better. The exit wound could kill someone in minutes. I wouldn't have a clue what to do really. For the shock one I think could be a bit better, but shock is something I can barely remember being taught (3)

\section{Training needs}

SCs believed it was a joint individual and organisational responsibility to maintain levels of knowledge.

You are never going to be able to say to an individual that it is your responsibility. There are too many things going on in their lives. If you're part of an organisation then there is a responsibility to the organisation if they want you to preserve life, they must have a prime responsibility (9)

SCs' views of the current training system appear to vary, with some believing that the current training is adequate and that they should not be expected to do anything more.

How much more can you teach, it's a case of that I'm a walking talking law machine, a policeman, suddenly preserving life, we can't do everything as we are only human at the end of the day (2)
However, the most common view of the SCs was that first aid training should be more extensive, considering the ever-changing and adapting roles of the SC.

The one limitation on the first aid training is the fact that it is first aid training and perhaps what might be done in the future is that because as police officers we seem to be expanding more and more, we have to be paramedics, social workers and psychologists (1)

Another SC expressed how rushed training had a negative impact on the amount they learnt.

I feel it's a rushed procedure, very much get in, get out, and not taking enough time to make sure we have fully understood what was going on. (10)

\section{Continuity of training}

Many of the participants believed there was a need for training frequency to be increased to either 6 monthly or even 3 monthly.

I think 6 monthly training would probably be better as opposed to annually because it is such an important part of what we do. (7)

I think around 3 months or so, because 6 months is too long, because once you start having training every 3 months you still remember rather than 6 months (6)

The reason given as to why more regular training was needed was that the training received is not used every day and is often forgotten after a period of time.

...you're not dealing with these [first aid] situations everyday so a lot of POs may forget (4)

One SC commented on the recently introduced online training packages which aimed to help improve the frequency of training through other means. This SC felt that, although online training was helpful, it could not replace practical training.

The actual day was more useful but online helps you remember stuff from the day, it refreshes your memory. (5)

Some participants suggested that extra training could be given 'on the job' during the day-to-day shifts.

...during a shift if there could be a little extra training, just to run through the major areas which police encounter on a day-to-day that would increase confidence (11)

\section{Other available training courses}

One alternative to increasing the frequency of training by the police that was discussed was attending training provided by outside agencies. Some SCs felt the 'outside' courses they had attended were just as good as the metropolitan police course. 
It was by and large the same, the same techniques and same principles, I didn't notice a significant departure (11)

However, several other SCs pointed out that other courses were better and more structured.

I went with St John's ambulance, they put you in a room and showed you scenarios that are hard to deal with and they go through it with you and are very strict with what to do. If you do it wrong, you do it again. I think it was more structured. (10)

It appeared that some SCs felt that the police training course was lacking in certain aspects, including mental health.

...mental health is a huge part of what we deal with on a daily basis and that's not covered at all. That's really poor because I've dealt with several mental health patients in ten months and on no occasions I knew what to do or how to deal with them. I felt very underprepared and I've then gone off myself to study how to deal with them in future. (10)

\section{DISCUSSION}

SCs are often de facto first responders in situations where a member or members of the public have medical needs. Little is known about how SCs view their responsibility or whether they feel prepared to undertake this responsibility. In common with other qualitative studies, this study is not intended to sample the views of a representative sample of the wider population of SCs, but rather provide a more detailed 'insider perspective' of how officers cope in such circumstances. The study identified four inter-related themes which connect views of their responsibility, confidence in delivering their role, knowledge and training needs.

A major theme identified in the study was that all the participants felt that they had a responsibility to preserve life by providing first aid, although the degree of importance given to this varied. This is consistent with Hawkins et $a l,^{5}$ who found $73 \%$ of police officers believed it was a key role. There were a variety of beliefs about why they had this responsibility. While some believed it stemmed from a moral or legal duty, there was also a belief that it arose from public expectations. Many SCs believed that, because of this responsibility, they had a duty to be knowledgeable about first aid.

The second major theme identified in the study related to the confidence of SCs in undertaking this role. SCs expressed varying levels of confidence in undertaking their first aid role. This is consistent with Groh et $a l,{ }^{4}$ who found that only $35.6 \%$ of police officers feel confident in dealing with cardiac events. There were a number of aspects that seemed to be important in determining whether SCs felt confident. While past experience, both inside and outside their roles as SCs, was seen as important, situational factors were also important in determining SCs' confidence in delivering first aid. However, the situational factors did not relate to just the technical difficulty of the first aid, but also to feeling supported both practically and emotionally by colleagues and by having access to appropriate equipment. SCs also believed that the level of training they received was important in improving confidence in terms of both its frequency and breadth.

The third major theme identified was related to SCs' first aid knowledge. SCs believed that their personal first aid knowledge came from both personal experience and their training. However, exploration of this with the aid of vignettes demonstrated some variation in the level of knowledge. This is consistent with the findings of Sztajnkrycer et $a l^{6}{ }^{6}$ who found that, on occasions, police officers' competency did not reach the expected standard. SCs reflected on their past performance, with some SCs believing they had performed to the best of their capability and little could be done to improve their knowledge. However, many SCs critically evaluated their personal knowledge and expressed a wish to develop their knowledge.

The fourth major theme related to perceived training needs. Many SCs believed they had training needs but that it was predominantly the responsibility of the police force to provide adequate training. The majority believed that the training should be improved. There was a belief that the continuity of training needed to be better, with SCs having regular refresher courses. Some SCs suggested that courses provided externally by other emergency services were better. There is some support for this from Pfeffer et $a l^{7}{ }^{7}$ who found that combining the first aid training of police officers with other 'emergency medical services' personnel improved the standard of first aid performed by police officers.

\section{Strengths and limitations}

A strength of the study was that it provided an in-depth exploration of views held by SCs regarding their roles as first aiders. Little is known about the first aid readiness of this group of first responders. JSC was an SC working in the same police station as the sample studied. The researcher was a part of the social group being studied and as such shared many of their experiences, assumptions and beliefs. This allowed the researcher to have a shared understanding of the issues involved and to be a trusted member of the group, which may have facilitated the exploration of these issues. However, this may also have coloured the researcher's analytical interpretation. This was addressed by the data being analysed independently by the second author (RM) and the final thematic framework being agreed by both authors.

The sample was recruited from one police station in the metropolitan police force area in which the researcher was working as an SC. It may have been that, had the sample been recruited from a number of police stations, more themes would have been identified. However, we believe that it is likely that theoretical 
saturation was achieved with the chosen sample, as no new ideas emerged from the last four interviews.

The main data were collected from face-to-face interviews between the researcher and the sampled SCs. This was triangulated with data from participant observation of events by the researcher (JSC) while in his role as an $\mathrm{SC}$; this was enhanced by a reflective diary kept by the researcher during the study period.

\section{Implications}

It is only possible to draw tentative conclusions from a small qualitative study. However, if the findings are confirmed by further research including quantitative methodologies using larger samples, then more generalisable conclusions may be drawn. This study suggests implications for the role and education of SCs as first responders.

The study identified that SCs believe first aid is a part of their duty and, in order to perform it correctly, they must have both the necessary skills and the confidence to carry out these skills effectively. Improving SCs' confidence in such situations may include their attending potential first responder situations in pairs when manpower allows. SCs should also be provided with the necessary equipment to perform the first aid tasks that they may encounter. Linked to this, first aid kits should be checked regularly to ensure they are complete and that they meet the necessary standards.

In relation to training, while it is important to ensure SCs have the appropriate first aid skills, it also important that they understand the background to their role. While it may be acceptable for SCs to hold varying beliefs about moral responsibility and public expectations, it is clearly important that they understand their legal duties, and the study suggests further training on this aspect may be necessary. The study also suggests that more frequent refresher training may be necessary to maintain first aid skills among SCs. Consideration could be given to joint training with other emergency services to enhance coordination and knowledge.

\section{CONCLUSIONS}

This study has provided some interesting insights into beliefs of SCs about their role, their confidence in delivering their role, and their perceived training needs. Clearly, qualitative studies in more diverse samples may identify other themes, and larger quantitative studies would be needed to assess the generalisability of these themes. However, this study provides data that may be of interest to those responsible for first aid training in the metropolitan police force, and, if it proves to be generalisable, may have a significant impact on the first aid training of SCs and other police officers and consequently enhance the safety of the public in situations where the police act as first responders.

Acknowledgements Special thanks go to the Metropolitan Police and the Metropolitan Police Special Constabulary for allowing JSC to interview special constables. Thanks must also go to the Metropolitan Police Research Department who were able to offer advice, guidance and approval for this project. In particular, within the Metropolitan Police Services, thanks go to Andy Rowell (Borough Commander), Joe Thompson (Metropolitan Police Research Department) with the rest of the Research Department Team, Sue Warner (Head of First Aid Training at the Metropolitan Police) and Jo Rapley (Special Constabulary Coordinator), all of whom were able to provide support for this project. Finally, I would like to thank all of the participants who gave their time to take part in this study.

Contributors JSC was the main author who designed, carried out and analysed the data and was the main author for the write-up. RM was the supervisor who helped with every stage, in particular the designing and analysis, as well as providing input in the write-up.

Funding This research received no specific grant from any funding agency in the public, commercial or not-for-profit sectors.

Competing interests None declared.

Ethics approval University College London Ethics/Metropolitan Police Ethics.

Provenance and peer review Not commissioned; externally peer reviewed.

Data sharing statement No additional data are available.

Open Access This is an Open Access article distributed in accordance with the Creative Commons Attribution Non Commercial (CC BY-NC 4.0) license, which permits others to distribute, remix, adapt, build upon this work noncommercially, and license their derivative works on different terms, provided the original work is properly cited and the use is non-commercial. See: http:// creativecommons.org/licenses/by-nc/4.0/

\section{REFERENCES}

1. B.T. (British Telecoms). Review of 999 calls. 2012. http://www.btlife. bt.com/technology-and-communication/happy-birthday-999 the-uks-emergency-call-service-turns-75/ (accessed 15 Mar 2013).

2. Home Office. Review of Police Leadership and Training. 2011. http:// www.homeoffice.gov.uk/publications/consultations/ rev-police-leadership-training/report?view=Binary (accessed $10 \mathrm{Nov}$ 2012).

3. Macpherson W. The Stephen Lawrence Inquiry: report of an inquiry by Sir William Macpherson of Cluny. CM 4262-1. London: Stationery Office, 1993.

4. Groh WJ, Lowe MR, Overgaard AD, et al. Attitudes of law enforcement officers regarding automated external defibrillators. Acad Emerg Med 2002:9:751-3.

5. Hawkins SC, Shapiro AH, Sever AE. The role of law enforcement agencies in out-of-hospital emergency care. Resuscitation 2007;72:386-93.

6. Sztajnkrycer MD, Callaway DW, Baez AA. Police officer response to the injured officers: a survey-based analysis of medical care decisions. Prehosp Disaster Med 2007;22:335-41. http://journals. cambridge.org/abstract_S1049023X00004970

7. Pfeffer AN, Ramirez M, Lee G, et al. EMS Providers train local law enforcement agencies. Tennessee, 2012. http://www.jems.com/ articles/print/volume-37/issue-5/training/tenn-ems-providers-trainlocal-law-enfor.html

8. Pope C, Ziebland S, Mays N. Qualitative research in health care: analysing qualitative data. BMJ 2000;320:114-16. 